\title{
Effect of germination of finger millet on nutritional value of foods and effect of food supplement on nutrition and anaemia status in Tanzanian children
}

\author{
S.TATALA ${ }^{1 *}$, G. NDOSSI ${ }^{1}$, D. ASH ${ }^{2}$ and P. MAMIRO ${ }^{3}$ \\ ${ }^{1}$ Tanzania Food and Nutrition Centre, Ocean Road, P.O. Box 977, Dar es Salaam, Tanzania \\ ${ }^{2}$ University Research Company, Box 71561, Dar es Salaam, Tanzania \\ ${ }^{3}$ Sokoine University of Agriculture, Morogoro, Tanzania
}

\begin{abstract}
Inadequate dietary intake, often combined with an infection can lead to malnutrition that often manifest as growth failure or deficiency of essentials nutrients including iron leading to iron deficiency anaemia. In an effort to investigate diet in relation to nutrition status of children, diet and dietary intake were investigated in rural Tanzania. The effect of germination of finger millet based food recipe on its nutritional value was evaluated. The food consisted of finger millet flour, kidney beans, ground peanuts and dried mangoes at predetermined proportions of 75:10:10:5 respectively. Dietary habits of young children were investigated and effects of a fortified food supplement and the cereal based recipe on nutrition status of children were investigated. The two diets were then supplemented to children for 6 months and changes on anaemia and anthropometrical indices of children were evaluated at follow up periods. To assess anaemia and iron status, haemoglobin $(\mathrm{Hb})$, haematocrit $(\mathrm{Hct})$, erythrocyte protoporphyrin $(\mathrm{EP})$ and serum ferritin $(\mathrm{SF})$; and weights and heights were measured to assess growth. A significant improvement in nutrient density was noted in processed cereals. Bioavailability of iron in cereal based diet increased from $0.75 \pm 18$ to $1.25 \pm 41 \mathrm{mg} / 100 \mathrm{~g}(P=008)$, viscosity was significantly raised by $12 \%$ and phytate concentration was reduced from $4.5 \pm 0.5$ to $4.1 \pm 0.5 \mathrm{mg} / \mathrm{g}(P=0.03)$. Significantly lower intake of iron was observed in schoolchildren with $\mathrm{Hb}<11.5 \mathrm{~g} / \mathrm{dl}$ ) compared to those who were normal. Total iron intake was $22 \pm 7$ and $27 \pm 13 \mathrm{mg} / \mathrm{day}$, respectively $(P<0.05)$. There was a significant correlation between iron intake and serum ferritin $(\mathrm{r}=0.233, P<0.05)$. After six months of supplementing children with the fortified beverage a significantly larger increase in haemoglobin concentration was shown in the fortified group than in the non-fortified group (a difference of 6.2 versus $3.2 \mathrm{~g} / \mathrm{dl}$ respectively). Supplementing infants with the germinated cereal based food supplement showed a general improvement on $\mathrm{Hb}$ status and growth that was not significantly different to that in the control group $(P>0.05)$. In conclusion, consumption of foods with low iron bioavailability is a major cause of anaemia. Germination improves the nutritional value of foods however there is need to fortify such processed foods for infant feeding.
\end{abstract}

Key words: Iron, bioavailability, finger millet, germination, nutrient, anaemia, Tanzania

\section{Introduction}

Encouraging timely introduction of weaning foods that either enhance iron absorption or have been fortified with iron (DeMaeyer et al., 1985) has a potential of improving the iron nutrition status by its influence on bioavailability. Increasing intake of iron absorption enhancers such as ascorbic acid and meat increases iron absorption and have an impact on iron nutrition. The dietary factors influencing bioavailability include dietary iron content and type (haem or nonhaem), physico-chemical form of the food, other dietary constituents and food-processing techniques (Fairweather-Tait, 1995). Iron dose is inversely related to absorbed iron both with dietary iron and iron supplements provided the iron is in an assimilable form (Bothwell, 2000).

Presence or absence of inhibitors in the consumed meal influences absorption of nonhaem iron. Cereals exhibit inhibition of dietary iron absorption due to the endogenous phytate contained in their outer coats. During food processing (e.g. fermentation, germination, baking) and to a limited extent with the action of endogenous phytases in some cereals, phytic acid is dephosphorylated to yield lower inositol phosphates such as myoinositol bis-, tris-, and penta-phosphates (Torre et al., 1991). Removal of the phytate in bran by different methods increases iron absorption by approximately 3.5 times (Hallberg et al., 1987). Phytate in whole-grain cereals beans (legumes), nuts, and seeds reduce iron absorption in dose dependent manner, due to the formation of insoluble and / or indigestible complexes between iron, phytate, and proteins (Hallberg, 1981; Brune et al., 1992).

Traditional food processing methods not only improves iron bioavailability, but also gives the nutritional quality of food that is an essential nutritional synergy. Nutritional synergism effects of nutrients have been demonstrated by an effective reduction of the prevalence of anaemia when a combined iron and vitamin A supplementation is done than with iron supplementation alone (Suharno \& Muhilal, 1996; Suharno et al., 1993).

\footnotetext{
Correspondences: Dr Simon Tatala; E-mail : simontatala@netscape.net; tatala_s@lycos.com
} 
Low dietary iron intake has been an attributed cause of iron deficiency and anaemia in many parts of the developing world (WHO, 1992; De Maeyer, 1985). In infants and children, iron deficiency is associated with impaired psychomotor development, decreased cognitive function, and negative behavioural changes. These impairments have in the long run a serious adverse developmental and economic implication (Bosta, 1979). In developing countries intake of dietary iron appear to be high but most of this is of non-haem in origin (Salas et al., 1990; Monsen, 1988). The absolute amount of dietary iron in these situations is therefore less important than its availability in the type of meal in which it is found. When body iron stores are low, the absorption of non-haem iron increases, but this usually does not exceed $20 \%$ even when there is a concomitant ingestion of enhancers such as vitamin $\mathrm{C}$ and meat proteins (Monsen, 1988). Food absorption studies in humans have revealed that the absorption of haem iron is relatively unaffected by other dietary factors. Haem iron from animal products is absorbed at $15-35 \%$ of intake (Hallberg, 1981). However, enhancers as well as inhibitors of absorption influence to a larger extent the non-haem iron whose absorption is between 2 and 20\% (Hallberg, 1981). Dependence on plant based foods for iron nutrition may thus result into a high prevalence of iron deficiency, particularly in populations that are at risk like children and pregnant women who have higher needs (Cook et al., 1976; Yip 1988). There is therefore a need in understanding how dietary factors, including iron availability and intake, influence iron status.

Studies in Tanzania have indicated that there is a high amount of iron in cereals and vegetables consumed. However, this type of iron is usually of low bioavailability (Tatala et al., 1998; Lorri \& Svanberg, 1995). Our knowledge is limited on how the food consumption pattern in Tanzania is related to the prevalence of iron deficiency and anaemia. Hence, the objective of this study was to determine the impact of germination on improvement of the nutritional value of food and also to elucidate the relationship between foods or supplement intake on iron status among a sample of anaemic children in Tanzania.

\section{Methods and Methods}

\section{Study area and Subjects}

The study was conducted in rural settlements of Mpwapwa and Kilosa Districts in central Tanzania. In Mpwapwa the enrolment of school aged children (7 to 12 years) and follow up was from March to August 1996. In Mpwapwa apart from the use of the locally available foods children from 101 households were also randomly allocated to receive either a fortified or non fortified beverage $200 \mathrm{ml}$ daily for the follow up period. The fortified beverage contained iron, zinc, and iodine, and A, C, E and B-vitamins at physiological doses. In Kilosa, 300 infants recruited at the age of 6 months were enrolled and followed up from February to December 2001. These infants were also allocated into two groups randomly to receive processed finger millet based porridge or the unprocessed. The children under studies completed baseline measurements before the dietary intake data were collected. Final measurements were taken at the end of the follow up period for all children. Informed consent was obtained from parents and children to participate in the study. A structured profile questionnaire was used to collect nutrition particulars of children before the dietary survey. The studies were part of main studies being conducted in these areas (Latham et al., 2001; Mamiro et al., 2004).

\section{Study design and data collection}

Two designs were employed for this study; the use of randomised controlled trials for the impact study and experimental design for data collected in a dietary survey. A pre-tested, food frequency questionnaire (FFQ) was used for interviews in households on food intake and availability. The FFQ had a list of 35 food items identified from the community after market and household surveys. The FFQ included a list of food items (cereal staples) used for breakfast, lunch and dinner, and additional foods or snacks taken daily. The questions addressed were the number of days in a week the particular food was eaten in that household and the portion that was consumed by the index child per day.

Nutritionist trained to estimate food portion sizes using familiar utensils to the community under study were used to collect food intake data. The estimated portion sizes were then measured to determine the weights or 
volumes they translate to enable assessment of food intake. The FFQ was administered during personal interview with the mother or guardian. Food items / meals consumed in schools and away from homes (snacks, seasonal fruits / cassava pieces) were also enquired and recorded. Information on seasonal foods was obtained to assist in explaining a possible variation in intake. Food samples commonly consumed in households were collected in sealed plastic bags and stored frozen at $-20^{\circ} \mathrm{C}$ until analysed for total iron and iron solubility by an in vitro method.

In preparation of the processed supplementary food finger millet and kidney beans were initially soaked for 3 and 8 hours, respectively and then left to germinate for 48 hours at $30^{\circ} \mathrm{C}$ and $80 \%$ relative humidity, washed and then solar dried for three days. The solar dried sprouts were then milled into fine flour and mixed in proportions with ground roasted peanuts, kidney beans and solar dried mashed mango puree. The mixtures were mixed in proportions of $75 \%$ finger millet, $10 \%$ peanuts, $10 \%$ kidney beans and 5\% mango (on a dry weight basis). The beverage supplements used by school age children were industrially prepared and provided by Procter \& Gamble Co. USA.

The collected staple foods and mixtures of commonly used foods were analysed by an in vitro method that estimates iron bioavailability. The in vitro method is a physiologically simulated peptic-pancreatin digestion for soluble iron. Iron measurements were made on an atomic absorption spectrometer (PU 9100 X; Philips, Cambridge, UK). Total iron was determined after acid combustion in a microwave oven before it was analysed with HPLC (Waters, 600 $S$ Controller). All samples were analysed in duplicate.

Total phenol was determined by Prussian Blue method (Price \& Butler 1977). A weighed sample $(500 \mathrm{mg})$ was extracted in $10 \mathrm{ml}$ acidified methanol (1 vol\% conc. $\mathrm{HCl}$ in methanol) for 1 $\mathrm{h}$ under continuous stirring. This was followed by centrifugation at $3500 \mathrm{rpm}$ for $10 \mathrm{~min}$ and the clear supernatant was collected and thereafter analysed spectrophotometrically (Hitachi, U$1100)$. The extract $(0.1 \mathrm{ml})$ was diluted with 4.9 $\mathrm{ml}$ water followed by the addition of $0.3 \mathrm{ml} 0.1 \mathrm{M}$ $\mathrm{FeCl}_{3}$ in $0.1 \mathrm{M} \mathrm{HCl}$ and addition of $0.3 \mathrm{ml} 0.008 \mathrm{M}$ $\mathrm{K}_{3} \mathrm{Fe}(\mathrm{CN})_{6}$. The absorbance was read at $720 \mathrm{~nm}$ after $10 \mathrm{~min}$. Catechin was used as standard
$(0.05,0.075,0.1,0.125$ and $0.150 \mathrm{mg} / \mathrm{ml})$. The standard solutions $(0.1 \mathrm{ml})$ were also diluted with $4.9 \mathrm{ml} \mathrm{H}_{2} \mathrm{O}$ followed by in the same amounts as above.

To analyse phytate content HPLC method was used (Sandberg \& Ahderinne 1986). A finely ground sample of $0.5 \mathrm{~g}$ was accurately weighed in a plastic container and then $10 \mathrm{ml}$ of $0.5 \mathrm{M} \mathrm{HCl}$ was added. The contents were then extracted at room temperature while stirring for at least three hours. Then the sample was centrifuged at 3500 rpm for $10 \mathrm{~min}$ and supernatant separated before freezing. Analysis was made on HPLC (Waters, 6005 Controller) after filtration and dilution.

A colorimetric method was used to determine L- Ascorbic acid in flour samples. A finely ground sample of $2 \mathrm{~g}$ was accurately weighed in a tube and approximately $5 \mathrm{ml}$ meta-phosphoric acid was added. The tube was then shaken until a homogenous dispersion was obtained. More meta-phosphoric acid was added so the tube finally contained $10 \mathrm{ml}$ solution. Then the sample was mixed for 90 seconds, and centrifuged before the supernatant was filtered. The clear solution was immediately used for the assay avoiding precipitation of starch in the system. Then to $0.1 \mathrm{ml}$ of the sample solution were added, $1.5 \mathrm{ml}$ water and $1 \mathrm{ml}$ of a solution mixture of sodium phosphate/citrate buffer, pH 3.5, MTT [3-(4,5-dimethylthiazolyl-2)-2,5diphenyltetrazolium bromide], stabilisers) warmed up to $37^{\circ} \mathrm{C}$ added to two cuvettes. The mixture was then blended and then incubated for $6 \mathrm{~min}$ at $37^{\circ} \mathrm{C}$. While incubating a sample of blank cuvette were mixed with ascorbate oxidase spatula for 5 seconds every $2 \mathrm{~min}$. After $6 \mathrm{~min}$ the spatula was removed and the absorbance was read and noted for both the sample and sample blank. Thereafter $0.1 \mathrm{ml}$ of 5-methylphenazinium methosulphate was added and cuvettes mixed thoroughly and incubated at $37^{\circ} \mathrm{C}$ for $15 \mathrm{~min}$ in the dark. MTT-formazan was then measured spectrophotometrically. Immediately after the last incubation absorbance of the sample and sample blank were read.

For citric acid analysis, a finely ground sample of about $0.5 \mathrm{~g}$ is accurately weighed in a plastic container and $10 \mathrm{ml}$ of $\mathrm{H}_{2} \mathrm{O}$ (milliq) is added. Then the contents were extracted at room temperature while stirring for at least three hours. The sample was then centrifuged at 3500 
rpm and the supernatant was analysed by HPLC (Dionex, series 4599i) (Mollering, 1989).

Haemoglobin concentration $(\mathrm{Hb})$ was determined by a HemoCue haemoglobinometer (HemoCue AB, Ängelholm, Sweden) and zinc protoporphyrin levels were measured on site with an AVIV haematofluorometer (AVIV Biomedical Inc., Lakewood, NJ, USA) using finger prick blood samples. $\mathrm{Hb}$ measurement was done at an accuracy of $\pm 0.003 \mathrm{~g} / \mathrm{dl}$. Serum ferritin (SF) concentration was determined by the Elegance Amplified Enzyme Linked Immuno Sorbent Assay (ELISA) system (Bioclone Australia Pty. Ltd). Serum C-reactive protein (CRP) concentration was also determined by the ELISA system. The analyses for SF and CRP were performed at a precision with a coefficient of variation of $<10 \%$. All analyses were performed within one month of collection (Tietz, 1995).

Stool and urine samples were screened microscopically for helminthic ova. Stool examination was done by the Kato-Katz method. Samples were examined on the same day of collection. Children found with helminthic infections were treated with $400 \mathrm{mg}$ albendazole. Children with schistosomiasis were treated with praziquantel $(40 \mathrm{mg} / \mathrm{kg}$ body weight). All children with splenomegaly and or history suggestive of malaria, and severe anaemia were referred for diagnosis and treatment in the nearby health centre (WHO, 1992).

Weight and height were measured with children in light clothing to the nearest 0.1 unit. A Seca electronic scale (standing or hanging, calibrated in $\mathrm{kg}$ ) and a fixed base portable stadiometer (in $\mathrm{cm}$.) or length board respectively were used for the measurements. Age was calculated from the birth date on school records or was obtained from birth certificates. A medical doctor conducted clinical examinations.

\section{Data analysis}

Data were entered using Excel and were managed and analyzed by SYSTAT statistical package (SYSTAT Inc.1997). Means and standard deviations (SD) of all measured intakes for the total group of children with anaemia and without anaemia were compared using the Student's ttest. Correlation between iron intake, iron status and the measured variables were considered significant when the level was $P$-value of $\leq 0.05$. The cut off level of iron intake used to categorise the different groups was $23 \mathrm{mg} /$ day which is recommended for children in the age between 6 and 12 years on diet with an estimated low bioavailability $(5 \%)$. Means of continuous variables were compared using Student's $t$ test. Nutrient intake data was analysed manually and by using the Microsoft Excel computer software programme. The FAO Food composition table for use in Africa was used to calculate nutrient intakes. Recommended dietary intakes (RDI) by age and sex were compared to those of $\mathrm{FAO} /$ WHO (1988) to assess the adequacy of diets and individual's nutrient intakes. Percentage iron solubility was obtained by calculating the ratio of soluble iron after digestion to the total iron in the respective foods.

\section{Ethical consideration}

Communal or parental consent was obtained in meetings with the District Officials, village councils, schoolteachers and parents. The purpose and details of the studies were explained to the relevant parties. Research and Ethics Committee of the Tanzania Food and Nutrition Centre approved the studies.

\section{Results}

The mean daily energy and nutrient intakes were found to be within the acceptable range for this group of children (Table 1). Mean iron intake for boys was $27 \pm 11 \mathrm{mg} /$ day and $24 \pm 10$ $\mathrm{mg} /$ day for girls. The iron intake was above the recommended intake of $15 \mathrm{mg} /$ day for children in the age range but $50 \%$ of schoolchildren had iron intake below the RDI for FAO/WHO of 23 $\mathrm{mg} /$ day for low bioavailability (5\%) diets. Energy intake was higher in boys than in girls $(P=0.08)$. Similarly, a significantly $(P<0.05)$ higher intake of vitamin $C$ was reported in boys compared to that in girls. 
Table 1: Daily mean $( \pm S D)$ nutrient intake of schoolchildren in Mpwapwa District grouped by sex

\begin{tabular}{|c|c|c|c|}
\hline Nutrients & Boys $(n=40)$ & Girls $(n=61)$ & All children $(n=101)$ \\
\hline Iron $(\mathrm{mg}) \%$ below cutoff ${ }^{1}$ & $27 \pm 11(47.5)$ & $24 \pm 10(54.1)$ & $25 \pm 11(51.5)$ \\
\hline Vitamin C (mg) & $51 \pm 31^{\mathrm{a}}$ & $32 \pm 27^{b}$ & $39 \pm 36$ \\
\hline Carbohydrates (g) & $295 \pm 92^{a}$ & $249 \pm 100^{b}$ & $290 \pm 100$ \\
\hline Fat $(\mathrm{g})$ & $94 \pm 50$ & $77 \pm 60$ & $84 \pm 60$ \\
\hline $\begin{array}{l}\text { Protein }(\mathrm{g}) \\
\% \text { below cutoff }{ }^{1}\end{array}$ & $\begin{array}{l}73 \pm 33 \\
10.0\end{array}$ & $\begin{array}{l}62 \pm 29 \\
(21.0)\end{array}$ & $\begin{array}{l}67 \pm 30 \\
16.9\end{array}$ \\
\hline $\begin{array}{l}\text { Energy (Kcal) } \\
\% \text { below cutoff }{ }^{1}\end{array}$ & $\begin{array}{l}2150 \pm 770 \\
40.0\end{array}$ & $\begin{array}{l}1830 \pm 895 \\
62.3\end{array}$ & $\begin{array}{l}1960 \pm 860 \\
53.5\end{array}$ \\
\hline Fibre (g) & $23 \pm 14^{\mathrm{a}}$ & $17 \pm 9^{b}$ & $20 \pm 13$ \\
\hline
\end{tabular}

${ }^{1}$ Below FAO / WHO recommended daily intake; Means followed by different letters are significantly different at $P<0.05$

Table 2: Daily mean $( \pm \mathrm{SD})$ nutrient intake of schoolchildren of Mpwapwa grouped by their iron status

\begin{tabular}{|c|c|c|c|c|c|c|}
\hline \multirow[t]{2}{*}{$\begin{array}{l}\text { Nutrient } \\
\text { Intake }\end{array}$} & \multicolumn{2}{|c|}{$\begin{array}{l}\text { Serum ferritin } \\
\qquad(\mu \mathrm{g} / \mathrm{L})\end{array}$} & \multicolumn{2}{|c|}{$\begin{array}{l}\text { Erythrocyte protoporphyrin } \\
\quad(\mu \mathrm{mol} / \mathrm{mol} \text { haem })\end{array}$} & \multicolumn{2}{|c|}{$\begin{array}{l}\text { Haemoglobin } \\
\text { (g/dl) }\end{array}$} \\
\hline & $\begin{array}{l}\mathrm{Low}^{1} \\
(\mathrm{n}=30)\end{array}$ & $\begin{array}{l}\text { Normal } \\
(\mathrm{n}=50)\end{array}$ & $\begin{array}{l}\text { High }^{2} \\
(n=20)\end{array}$ & $\begin{array}{l}\text { Normal } \\
(n=60)\end{array}$ & $\begin{array}{l}\text { Anaemic }^{3} \\
(\mathrm{n}=38)\end{array}$ & $\begin{array}{l}\text { Normal } \\
(\mathrm{n}=42)\end{array}$ \\
\hline Iron $(\mathrm{mg})$ & $23 \pm 8^{a}$ & $26 \pm 10$ & $22 \pm 8^{a}$ & $26 \pm 11$ & $22 \pm 7^{a}$ & $27 \pm 12$ \\
\hline Vitamin C (mg) & $29 \pm 21$ & $41 \pm 29$ & $30 \pm 16$ & $39 \pm 16$ & $40 \pm 29$ & $37 \pm 27$ \\
\hline Carbohydrate(g) & $228 \pm 72$ & $282 \pm 96$ & $225 \pm 65$ & $279 \pm 96$ & $255 \pm 91$ & $290 \pm 103$ \\
\hline Fat $(\mathrm{g})$ & $77 \pm 40$ & $96 \pm 62$ & $64 \pm 48$ & $98 \pm 59$ & $78 \pm 44$ & $89 \pm 67$ \\
\hline Protein (g) & $61 \pm 23$ & $69 \pm 34$ & $47 \pm 18$ & $74 \pm 31$ & $61 \pm 27$ & $73 \pm 31$ \\
\hline $\begin{array}{l}\text { Energy (kcal) } \\
\text { Dietary fibre (g) }\end{array}$ & $\begin{array}{c}1764 \pm 571^{\mathrm{a}} \\
18 \pm 12\end{array}$ & $2076 \pm 83219 \pm 9$ & $\begin{array}{c}1612 \pm 560^{a} \\
14 \pm 8\end{array}$ & $2105 \pm 85021 \pm 10$ & $\begin{array}{c}1891 \pm 675^{a} \\
18 \pm 10\end{array}$ & $\begin{array}{c}2159 \pm 956 \\
19 \pm 11\end{array}$ \\
\hline
\end{tabular}

Schoolchildren with anaemia (low $\mathrm{Hb}$ ) had a significantly lower iron intake than those without anaemia $(22 \pm 7$ versus $27 \pm 12 \mathrm{mg}$ / day) $(P<0.05)$ (Table 2). A similar finding was for erythrocyte protoporphyrin (EP) in which significantly lower iron intake was found in children with abnormal $\mathrm{EP}$, but not for serum ferritin (SF). There was also a significantly $(P<0.05)$ higher energy intake in children with normal $\mathrm{Hb}$ compared with those with low $\mathrm{Hb}(2159 \pm 956$ vs. $1891 \pm 675 \mathrm{kcal} /$ day), as well as in children with normal compared with those with abnormal EP ( $2105 \pm 850$ vs. $1612 \pm 560$ $\mathrm{kcal} /$ day respectively). 
Table 3: Food iron content and in vitro iron solubility from foods regularly consumed by children in the study areas ${ }^{1}$

\begin{tabular}{|c|c|c|c|}
\hline \multirow[t]{2}{*}{ Food item } & \multirow{2}{*}{$\begin{array}{c}\text { Total iron } \\
\text { (mg /100 g d.m.) }\end{array}$} & \multicolumn{2}{|c|}{ Iron solubility ${ }^{1}$} \\
\hline & & (mg/100 g d.m.) & $(\%)$ \\
\hline \multicolumn{4}{|l|}{ Cereals } \\
\hline Finger millet & 3.1 & $0.43 \pm 0.03$ & 12.6 \\
\hline Maize porridge & 14.4 & $0.17 \pm 0.05$ & 1.2 \\
\hline Sorghum porridge & 6.0 & $0.16 \pm 0.06$ & 2.6 \\
\hline \multicolumn{4}{|l|}{ Legumes } \\
\hline Kidney beans & 7.9 & $2.25 \pm 0.05$ & 27.9 \\
\hline Mung beans & 5.7 & $1.17 \pm 0.05$ & 20.5 \\
\hline Cowpeas & 5.9 & $1.64 \pm 0.01$ & 28.0 \\
\hline \multicolumn{4}{|l|}{ Vegetables } \\
\hline Cowpea leaves & 48.8 & $5.10 \pm 0.02$ & 13.0 \\
\hline Amaranth leaves & 72.6 & $4.81 \pm 0.05$ & 6.6 \\
\hline Cassava leaves & 6.2 & $0.37 \pm 0.01$ & 6.0 \\
\hline \multicolumn{4}{|l|}{ Meal Mix $(80: 20)^{2}$} \\
\hline Maize+amaranth & 23.1 & $1.17 \pm 0.09$ & 5.1 \\
\hline Maize+kidney beans & 13.1 & $0.37 \pm 0.01$ & 2.8 \\
\hline Maize+mung beans & 12.6 & $0.31 \pm 0.02$ & 2.7 \\
\hline Maize+cowpeas & 19.6 & $0.83 \pm 0.01$ & 4.2 \\
\hline
\end{tabular}

${ }^{1}$ Mean of replicate samples analysed in duplicates; ${ }^{2}$ Dry weight ratio of cooked mixture

In vitro iron solubility in foods consumed by these children ranged from 0.16 in cereals to 5.1 $\mathrm{mg} / 100 \mathrm{~g} \mathrm{dm}$ in vegetables and the percentage solubility ranged from $1.2 \%$ in cereals to $28 \%$ in legumes (Table 3). When composite diets of maize gruel and legumes were analysed in the way they are consumed the highest in vitro iron solubility was about $5 \%$. Nutritional value of unprocessed food was significantly lower than for processed cereals (Table 4). Phytate concentration in the complementary food was significantly reduced from $4.5 \pm 0.5$ to $4.1 \pm 0.5 \mathrm{mg} / \mathrm{g}(P=0.03)$ and raising soluble iron, viscosity and protein digestibility $(P<0.05)$.

The dietary sources of iron showed that plant based-foods including cereals and vegetables were contributing to $85 \%$ of the dietary iron in the children. The proportion of foods containing nuts and seeds appeared to be higher in the non-anaemic group compared to anaemic group but the difference was not significant $(P=0.174)$.

Table 4: Nutritional content of the supplementary food by comparing the processed and unprocessed germinated finger millet

\begin{tabular}{lccc}
\hline Nutrient/anti-nutrient & Unprocessed & Processed & P-value \\
\hline Total iron $(\mathrm{mg} / 100 \mathrm{~g})$ & $16.3 \pm 7.9$ & $21.1 \pm 11.1$ & Ns \\
Soluble iron $(\mathrm{mg} / \mathrm{100g})$ & $0.75 \pm 0.18$ & $1.25 \pm 0.41$ & 0.008 \\
Total phenol $(\mathrm{mgCE} / 100 \mathrm{~g}$ & $321 \pm 58$ & $322 \pm 44$ & $\mathrm{Ns}$ \\
Phytate $(\mathrm{mg} / \mathrm{g})$ & $4.5 \pm 0.5$ & $4.1 \pm 0.5$ & 0.03 \\
Ascorbic acid (mg/100g) & $0.04 \pm 0.04$ & $0.02 \pm 0.03$ & Ns \\
Citric acid (mg/g) & $9.3 \pm 0.3$ & $7.3 \pm 0.1$ & 0.03 \\
Viscosity $(\%)$ & $10 \pm 3$ & $22 \pm 4$ & $<0.05$ \\
Protein digestibility $(\%)$ & $65 \pm 4$ & $76 \pm 7$ & $<0.05$ \\
\hline
\end{tabular}

$\mathrm{P}<0.05$ significant differences between the processed and unprocessed finger millet based complementary food 
A screening for intestinal helminths showed positive findings in $2.6 \%$ of the children with no significant difference between the anaemic and non-anaemic groups. Stunting was present in $48 \%$ of the investigated school aged children $(\mathrm{n}=101)$ and in $59 \%$ of those who were anaemic $(\mathrm{n}=42)$. Mean HAZ and body mass index were not significantly different between children in the anaemic and non-anaemic groups. There was a significant improvement in $\mathrm{Hb}$ and anaemia status in schoolchildren taking the fortified beverage after 6 months of supplementation (Table 5). However, in the trial whereby infants were receiving the processed complementary food no significant differences was observed between the groups at the end of the follow up period. poisoning is not prevalent in these rural areas (Yip et al., 1983). The most significant predictor of haemoglobin status for these children was the daily iron intake as indicated by the stepwise multiple regression analysis. This finding supports the nutritional contribution to the anaemia aetiology in this community. This has also been reported in Lindi (Tatala et al., 1998) and Zanzibar (Stoltzfus et al., 1997) studies.

A high intake of vitamin $C$ reported in this study was expected to improve the iron availability from the diet. However, the foods containing vitamin $\mathrm{C}$ tended to be taken outside the main meal times, thus not providing the expected effect of enhancing iron absorption (Hallberg et al., 1986). The reported high mean intake of ascorbic acid is explained by the high

Table 5: Change in haemoglobin and anaemia status between baseline and follow up at 6 months for schoolchildren on micronutrient supplementation

\begin{tabular}{lcccc}
\hline & \multicolumn{2}{c}{ Haemoglobin status (g/d) } & \multicolumn{2}{c}{ Anaemia status (\%) } \\
\hline Non fortified & Fortified & Non fortified & Fortified \\
\hline Follow up ${ }^{1}$ & $11.97 \pm 1.21$ & $11.92 \pm 1.30$ & 19.1 & 18.5 \\
Change noted & $11.29 \pm 1.30$ & $11.60 \pm 1.22$ & 35.6 & 26.3 \\
\hline
\end{tabular}

${ }^{1}$ The findings at follow up were showing significant differences between the Non fortified and Fortified groups

\section{Discussion}

The study showed that iron deficiency is a serious problem among Tanzanian children, an observation that has also been reported by other studies (Stoltzfus et al,. 1997; Crompton, 1986). Iron intake was significantly lower in children who had anaemia, implying that iron intake was marginal in them. Although the iron intake was high compared with the recommendation for a diet with intermediate iron bioavailability, the high prevalence of anaemia might thus be a result of consumption of a diet with low iron bioavailability. In fact, half of these children had iron intake below the RDI by FAO/WHO of $23 \mathrm{mg} / \mathrm{d}$ for children on diet with low iron bioavailability. A lower iron intake was also found in children with abnormal (high) levels of EP. EP is a measure of adequacy of iron nutrition in the functional compartment of the body where $\mathrm{Hb}$ is being utilised. Though an elevated EP concentration could also be associated with chronic inflammation or lead poisoning, lead consumption of locally growing vitamin C-rich fruits which were in season. Measurement of in vitro iron availability in the commonly consumed foodstuff showed that solubility (a measure of bioavailability) ranged from $1.2 \%$ in cereals to $28 \%$ in legumes, but when composite diets were analysed, the meal with highest in vitro iron solubility contributed only $5 \%$ of the available iron. This finding was also shown in the Lindi study in Tanzania where similar foods are consumed (Tatala et al., 1998). In in vitro studies done on Tanzanian food sources have shown that the staple foods for most Tanzanians have a low percentage of available iron (Svanberg et al., 1993).

In our study there was a significantly higher energy intake in boys than in girls $(P<0.05)$ and also a high intake of dietary fibre, showing a possible high food intake by boys. A high intake of fibre in vegetable based diets has also been observed in a study among vegetarians elsewhere (Alexander et al., 1994). Vegetarians with similar eating habits to the subjects reported 
in this study also had a high mean iron intake than omnivores. In the vegetarian studies, like in our study a significantly high iron intake in male subjects than in female was observed (Alexander et al., 1994)

Plant-based foods including cereals and vegetables have an influence on energy and iron intake in children as observed in our study. From these findings there is an indication that low dietary iron availability is a major factor in anaemia causation, a finding that has been supported by in vitro studies on iron availability from their foods. The follow up study that looked into the nutritional value of infants food sources showed that cereal staples commonly used by most Tanzanians contain iron absorption inhibitors particularly tannins and phytate, that can be reduced by several traditional methods of food processing (Svanberg \& Lorri, 1993). Optimization and use of germination in the traditional way have shown an increase the percentage of available iron. These findings together with the observation that dietary iron availability is a problem, gives this community a sustainable option to reduce the problem of anaemia.

It is important for this community to embark on to a dietary approach in the control of childhood anaemia. Increasing intake of iron absorption enhancers such as ascorbic acid and meat will increase iron absorption and reduce anaemia. As noted in the tested fortified beverage there was a significant improvement in the $\mathrm{Hb}$ status of the school aged children. It is not expected that, poor rural people and especially the at risk group, whom iron deficiency is most prevalent, will increase significantly in the near future. However, dietary modification is important and small animal husbandry or poultry farming could be useful.

Germination has been shown by this study to improve iron accessibility. However, when this food preparation was supplemented to infants, reduction of the anaemia was not significantly different from that observed in the control group who were not receiving the optimized supplement. Absorption studies elsewhere have shown that an increase of iron uptake from 2.4 to $6.3 \%$ occurs after dehulling brown sorghum and addition of ascorbic acid to the meals (Hallberg et al., 1986). Soaking, germination and lactic acid fermentation may create optimal conditions for endogenous phytase in cereals. Phytases that hydrolyse phytate into lower inositol phosphates are present in most cereals and are activated during fermentation and germination. The fermentation and germination processes improve the amount of soluble iron and increase food iron bioavailability from low to the intermediate level (Cook et al,. 1986). Our findings indicate that improving dietary iron bioavailability will reduce iron deficiency and could reduce anaemia. This strategy combined with others such as food fortification and control of blood depleting diseases will effectively improve the nutrition status of these rural children.

The FFQ method used in our study may have exaggerated intakes in some individuals and underestimated in others, resulting in an overestimate of the proportion of children whose intakes fall below the recommended nutrient intakes, thus misclassifying individuals with low intakes or otherwise. However, the group intake data has helped in explaining the association between dietary iron intake and iron status of the sampled schoolchildren. FFQs allow assessment of long term or usual food intake over a month or year. This way it reduces errors introduced by estimating usual intake from the day to day variability in 24-h recalls. The FFQ used was designed based on food consumption in this Tanzanian community. To avoid miscommunication the designing took into consideration the cultural background of the community.

It may therefore be concluded from this study that iron intake contributes to the iron deficiency anaemia among Tanzanian children. It is therefore recommended that increased intake of bioavailable iron should be one of the strategies for the prevention of iron deficiency anaemia. To achieve this, the options are improvement of household food processing methods including germination and fermentation to enhance iron absorption from foods. Food fortification and deliberate addition of iron to enrich cereal staple foods used in child feeding should also be considered. People should be educated on the usefulness of traditional methods of processing foods in improving iron nutrition and nutrition status. 


\section{References}

Alexander, D., Ball, M.J. \& Mann, J. (1994) Nutrient intake and hematological status of vegetarians and age-sex matched omnivores. European Journal of Clinical Nutrition 48, 538-546.

Bosta, S.S. (1979) Iron deficiency anaemia and the productivity of adult males in Indonesia. American Journal of Clinical Nutrition 32, 916-925.

Bothwell, T.H., Baynes, R.D., MacFarlane, B.J. \& MacPhail, A.P. (1989) Nutritional requirements and food iron absorption. Journal of Internal Medicine 226, 357-365.

Bothwell, TH. (2000) Iron requirements in pregnancy and strategies to meet them. American Journal of Clinical Nutrition 72, 257s-264s.

Brune, M., Rossander-Hulten, L., Hallberg, L., Gleerup, A. \& Sandberg, A.S. (1992) Iron absorption from bread in humans; inhibiting effects of cereal fibre, phytate and inositol phosphates with different numbers of phosphate groups. Journal of Nutrition 122, $442-49$.

Cook, J.D. \& Monsen, E.R. (1976) Food iron absorption in human subjects. III. Comparison of the effect of animal proteins on non heme iron absorption. American Journal of Clinical Nutrition 29, 859-867.

Crompton, D.W.T. (1986) Nutritional aspects of infection. Transactions of the Royal Society of Tropical Medicine and Hygiene 80, 691705.

DeMaeyer, E. \& Adiels-Tegman, M. (1985) The prevalence of anaemia in the world. World Health Statistics Quarterly 38, 302316.

Fairweather-Tait, S.J. (1998) Bioavailability of Iron. In: Role of Trace Elements for Health Promotion and Disease Prevention (Sandstrom, B. \& Walter, eds.), Karger, Basel, pp. 29-39.

FAO/WHO (1988) Requirements of Vitamin A, Iron, Folate and Vitamin $B_{12}$. Report of a joint FAO/WHO Expert Consultation. p. 62-73. Food and Agriculture Organization of the United Nations, Rome, Italy.

Hallberg, L. (1981) Bioavailability of dietary iron in man. Annual Reviews of Nutrition
1, 123-147.

Hallberg, L., Brune, M. \& Rossander, L. (1986) Effect of ascorbic acid on iron absorption from different types of meals. Human Nutrition - Applied Nutrition 40A, 97-113.

Hunt, J.R., Mullen, L.M., Lykken, G.I., Gallagher, S.K. \& Nielsen, F.H. (1990) Ascorbic acid: effect on ongoing iron absorption and status in iron-depleted young women. American Journal of Clinical Nutrition 51, 649-655.

Kuvibidila, S., Yu, L., Warrier, R.P., Ode, D. \& Mbele, V. (1994) Usefulness of serum ferritin in the assessment of iron status in non-pregnant Zairean women of child bearing age. Journal of Tropical Medicine and Hygiene 97, 171-179.

Latham, M.C., Ash, D., Ndossi, G., Mehansho, H. \& Tatala, S. (2001) Micronutrient dietary supplements- a new fourth approach. Archivos Latinoamericanos de Nutrición 51, 37-44.

Lorri, W. \& Svanberg, U. (1995) An overview of the use of fermented foods for child feeding in Tanzania. Ecology of Food $\mathcal{E}$ Nutrition 34, 57-63.

Madanat, F., El-Khateeb, M., Tarawaneh, M. \& Hijazi, S. (1984) Serum ferritin in evaluation of iron status in children. Acta Haematologica 1, 111-115.

Mamiro, P.R.S., Van Camp, J., Mwikya, S.M. \& Huyghebaert, A. (2001) In vitro extractability of calcium, iron, and zinc in fingermillet and kidney beans during processing. Journal of Food Science 66, 1271-1275.

Mamiro, P.S., Kolsteren, P.W., Van Camp, J., Roberfroid, D.A., Tatala, S. \& Opsomer, A. (2004) Processed complementary food did not improve growth or haemoglobin status of rural Tanzanian infants from 6-12 months of age in Kilosa district, Tanzania. Journal of Nutrition 134, 1084-1090.

Mollering, H. (1989) Citrate. In: Methods of Enzymatic Analysis (Bergmeyer, HU ed) $3^{\text {rd }}$ ed Vol. VII, VCH Publishers UK, pp. $2-12$.

Monsen, E.R. (1988) Iron nutrition and absorption: dietary factors that impact iron bioavailability. Journal of American Dietetic Association 88, 786-790.

Price, M.L. \& Butler, L.G. (1977) Rapid visual estimation and spectrophotometric 
determination of tannin content of sorghum grain. Journal of Agriculture and Food Chemistry 25,: 1268-1273.

Reddy, M.B. Hurrel, R.F. \& Cook, J.D. (2000). Estimation of non haem iron bioavailability from meal composition. American Journal of Clinical Nutrition 71, 937-943.

Salas, J., Galan, P., Arija, V., Marti-Henneberg, C. \& Hercberg, S. (1990) Iron status and food intakes in a representative sample of children and adolescents living in a Mediterranean City of Spain. Nutrition Research 10, 379-390.

Sandberg, A-S. \& Ahderinne, R. (1986) HPLC method for determination of inositol tri, tetra-, penta-, hexaphosphates in foods and intestinal contents. Journal of Food Science 51, 547-550.

Soewondo, S., Husaini, M. \& Pollitt, E. (1989) Effects of iron deficiency on attention and learning processes in preschool children: Bandung, Indonesia. American Journal of Clinical Nutrition 50, 667-674.

Stoltzfus, R.J., Chwaya, H.M., Tielsch, J.M., Schulze, K.J., Albonico, M. \& Savioli, L. (1997) Epidemiology of iron deficiency anaemia in Zanzibari schoolchildren: the importance of hookworms. American Journal of Clinical Nutrition 65, 153-159.

Suharno, D. \& Muhilal, 1996. Vitamin A and Nutritional Anaemia. Food and Nutrition Bulletin 17, 7-10.

Suharno, D.,West, C.E., Muhilal, Karyadi, D.
\& Hautvast, J. (1993) Suplementation with vitamin A and iron for nutritional anaemia in pregnant women in West Java, Indonesia. Lancet 342, 1325-1328.

Svanberg, U., Lorri, W. \& Sandberg, A-S. (1993) Lactic fermentation of non-tannin and high tannin cereals: effect on in vitro iron availability and phytate hydrolysis. Journal of Food Science 58, 408-412.

Tatala, S., Svanberg, U. \& Mduma, B. (1998) Low dietary iron availability a major cause of anaemia: A nutrition survey in Lindi District of Tanzania. American Journal of Clinical Nutrition 68, 171-178.

Tietz, N.W. (1995) Clinical Guide to Laboratory Tests. $3^{\text {rd }}$ ed WB Saunders Company, Philadelphia, PA, 19106.

Torre, M., Rodriguez, A. \& Saura-Calixto, F. (1991) Effects of dietary fiber and phytic acid on mineral bioavailability. Critical Review in Food Science and Nutrition 1, 1-22.

WHO (1992) The Prevalence of Anaemia in Women: A Tabulation of Available Information. World Health Organization, Geneva.

Yip, R. \& Dallman, P.R. 1988. The Roles of Inflammation and Iron Deficiency as Causes of Anaemia. American Journal of Clinical Nutrition 48, 1295-1300.

Yip, R., Schwarts, S. \& Deinard, S. (1983) Screening for iron deficiency with erythrocyte protoporphyrin test. Pediatrics 72, 214219. 